\title{
A New Case for Clay: Multi-Dimensional High School Ceramics Billie Sessions
}

How can ceramics educators be better teachers? And how can they enhance the status of ceramics in education? ... You cannot advance the field of ceramics education unless you see it in relation to the goals of art as a whole and goals of general or liberal education.

Feldman, 1988, p. 21

\section{Introduction}

Ceramics in high schools has changed little in the past forty years. It is often focused on technique and process, seemingly concerned with educating the infrequent career artist rather than promoting the general education of students. My conviction, supported by the work of De Muro (1992) and Hill (1988), is that many high school ceramics programs are vestiges of outdated rationales, that address erroneous objectives, and are often only concerned with projects and techniques. There is a need to extricate and reconstruct conventional practices from their present position.

The potential of educating through ceramics has not been articulated in the field, accordingly ceramics education has been marginalized within art education. A change in methodology is proposed-moving from traditional ceramics instruction to instruction that meets the demands of education in a postmodem world. It is my premise, that to meet the needs of today's student, ceramics in schools should include many things beyond the conventional focus of process and pointless object-making.

This paper will characterize the problematic background of ceramics education followed by an abbreviated account of the development of a construct and description of research activities designed to advance a pedagogical shift in ceramics education. The central question for this study is, "What is the structure of the world of ceramics and how can the application of it guide how we view ceramic objects and ceramic instruction, thereby proposing a new case for clay?" The first part of the paper will briefly describe the background of the problem. The middle section of the paper will furnish a condensed account of the development of a construct ${ }^{1}$ designed to facilitate a new perspective for ceramics education. The last part of the paper will summarize how the construct was employed in the thesis research.

\footnotetext{
'Construct and structure are used interchangeably in this paper.
} 


\section{The Case for Clay in Art Education}

This study is dedicated to addressing key questions that were raised during The Case for Clay in Art Education, a 1988 national symposium, ${ }^{2}$

dedicated to focusing attention on the value of ceramics education in schools (Williams, 1988). Presentations at the symposium noted that a lack of supportive research on the educational value of ceramics had conceivably undermined ceramics education in school.

Conference keynote speaker Edmund Feldman commented, "If ceramics educators think they teach pot making for the sake of making pots, then they deserve educational oblivion" (1988, p. 21). Among the many presentations at the symposium, New York University art educator David Ecker asked in his topic, "If Clay is the Answer, What is the Question?" Four basic questions unfolded in his presentation: "What was the case for clay?, What is the case?, What could be the case?, and What should be the case" $(1988$, p. 20$)$ ? This research study is resolved to respond to Feldman's (1988) observation and Ecker's (1988) four questions.

\section{What Has Been the Case for Ceramics in Schools?}

It seems obvious that the aim of making pottery in a high school is not production for sale. The student is neither a professional craftsman nor a mature artist. ... To assume, from his [sic] involvement with the same materials. . . inhibits some students from using the ciass situation for growth and involves them in a frustrating battle to turn a learning situation into a producing one.

Powell, 1973, p. 23

Since the work of Peter Voulkos work in the 1950 s ceramics has become more securely positioned in the world of fine art. However, ceramics education has not become more securely positioned in art education or in schools. Current art education methodologies have been sluggish to address peripheral media such as ceramics; little has been published on ceramics education, particularly the capacity to education multi-contextually.

The research studies of De Muro (1992), Hill (1988) and Ropko (1977) emphatically pointed to technically oriented high school ceramics curricula; instruction that contributes little information to other aspects of the world of ceramics. For decades art educators and high school ceramic teachers have looked to the professional ceramic world and higher education as models for ceramic instruction in public schools. College ceramics courses are generally structured toward educational objectives that are ill-suited for high school students. College art education students, who will become high school ceramics teachers, do not have their pedagogical needs addressed within the general ceramic courses in higher education. Hill (1988) and De Muro (1992) stated that pre-student teachers acquire only technical skills, and gain little ability to articulate

\footnotetext{
${ }^{2}$ The symposium was cosponsored by Studio Potter and New York University
} 
a conceptual framework for teaching more than ceramics processes. Preteachers are not instructed on how to translate the studio-based model into content-based art education methodology and sound educational objectives for ceramic education.

The problem is then, there is no clear sense of the educational role/value of ceramics in art education or general education in today's schools. I believe this is the situation because: (a) the field of art education has not adjusted to a renewed respect for ceramics as an art form in the last half of the 20th century. (b) co-existing obsolete art education models do not satisfy today's educational situation, (c) outdated Modernist goals and language are deeply ingrained in school ceramics, (d) contemporary art education models (theories and methodologies) have neglected ceramics instruction, (e) sparse research exists concerning ceramics instruction and curricula, (f) high school ceramics instruction illogically models college ceramics courses, often thoroughly based on the studio model, and $(\mathrm{g})$ technique and process are the primary instructional and curricular focus, at the expense of time spent on other issues and information about art, ceramics and life outside of school.

\section{Dimensions of a New Case for Clay}

References, responses and expectations: these are what ceramics also evoke, in their own terms. And amongst those references are echoes of other ceramics and other art. ... Indeed our ceramic culture is filled with echoes.

Rawson, 1983, p. 13

Ceramic objects are, among many other things, reflections of ideas from their cultural origin (Clark, 1979; Cooper, 1979; Leach, 1948; Waiter, 1905), function (Hopper, 1986; MacKenzie, 1987), connections to the art world (Slivka, 1978, Alexander \& Day, 1991; Carpenter, 1995), and production considerations (Leach, 1948; Nelson, 1971; Rawson, 1984).

\section{The World of Ceramics: A Basic Structure}

As Rice (1990) and Clark (1983) have suggested, ceramic objects can be analyzed for content through universal lenses. If a ceramics object is placed in the center of a contextual arena for analysis, several questions may be asked about the object. Where, when and how was it made? What was its intended use? Who made it? How was it decorated and fired? What are its "roots?" Does it have a special meaning to the society? And lastly, does it have a relationship to other handmade artifacts? These questions indicate universal circumstances that ceramic objects share. They also indicate evidence of a contextual field for ceramics. Therefore, contextual lenses could be used to view all ceramic objects and a structure of the world of ceramics could be developed. Subsequently, the structure could be used to contextually examine the content of any ceramic object.

A conceptual model of a structure of the world of ceramics is advanced in this research. Figure 1 is a viable "structure of the world of ceramics." This

Marilyn Zurmuehlen's Working Papers In Art Education 1996-1997 


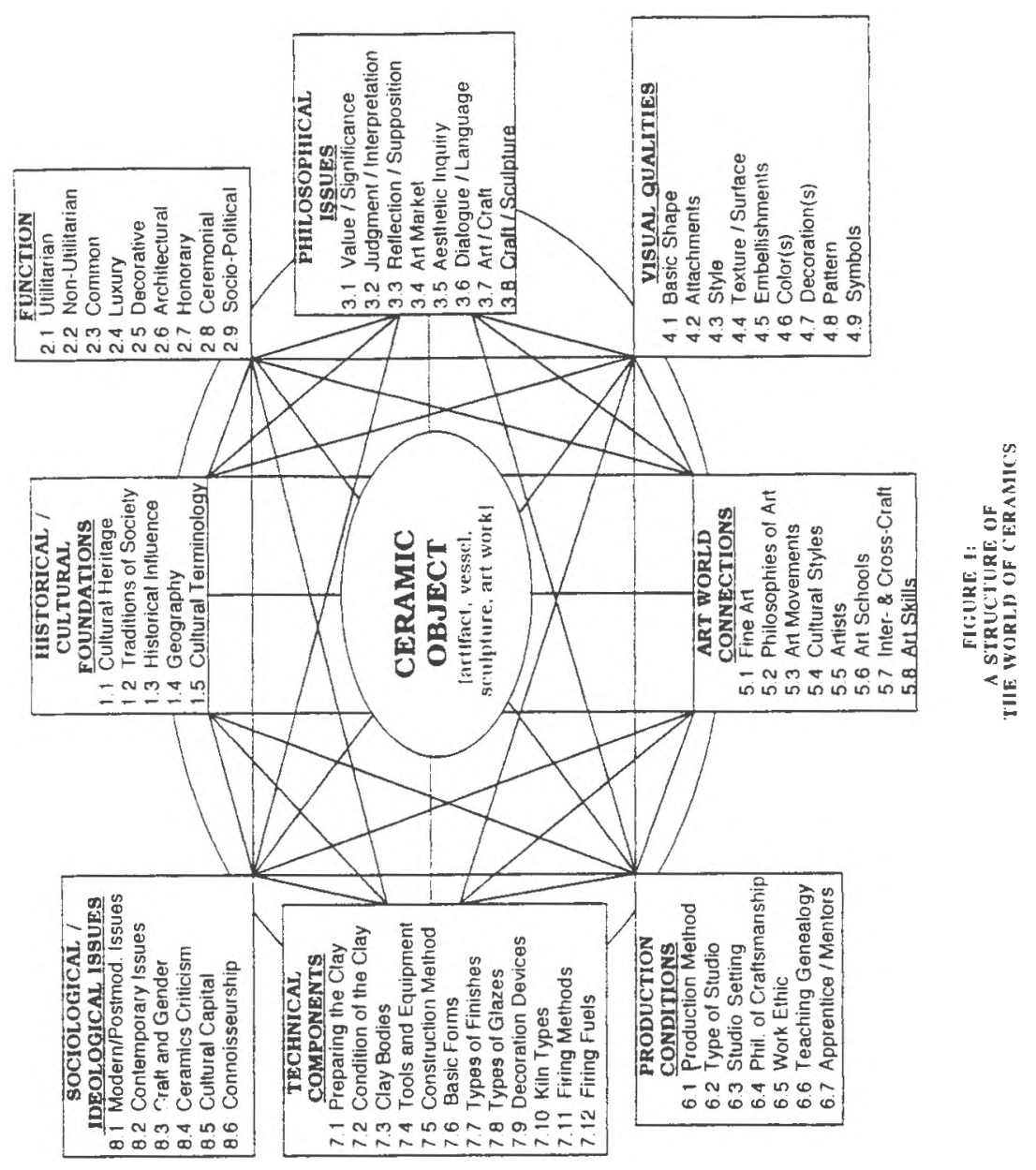


"construct" illustrates that ceramic objects reflect their cultural, social and technical circumstances whenever and wherever they are made; that they are carners of information and traditions from past times to the present; that they connect with other spheres of information outside as well as inside the art world

Eight domains have been identified as universal contextual lenses for ceramic objects and ceramics instruction. The domain topics represent what I have "systematically and objectively" (Stone, 1966, p. 13) identified as universal circumstances for mapping the text of any ceramic referent. The domains illustrate the interplay, intercontextuality. and reciprocity of the circumstances in the world of ceramics. Together the eight contextual avenues, with possible subtopics, provide an in-depth management system to analyze the circumstances of the object. Clearly, individual circumstances of each object impart a different contextual journey.

Each domain provides the opportunity to explore a particular aspect or circumstance of the world of ceramics: (1.0) Historical/Cultural Foundations-the cultural, historical, and geographical origins: (2.0) Function - why it was made?; (3.0) Philosophical Issues - the aesthetic issues; (4.0) Visual Qualities - its appearance; (5.0) Art World Connections - where and how it links to other media. artists, artifacts, and styles; (6.0) Production Conditions - the influence of the studio environment; (7.0) Technical Components - how it was made; and, (8.0) Sociological/Ideological Issues - critical relationships with society. ${ }^{3}$ Clearly, it is necessary to view the object through each lens or domain, however it is impossible to understand the object through only one domain.

The domain topics and subtopics work in two ways, (a) they provide the sources for questions that could be asked about an unknown text, and (b) they serve as guideposts for organizing information about the object. As inquiry sources, the eight topics can be turned into questions, for instance: What are the cultural foundations of this object? What is its function? What are the visual qualities? As guideposts the domains provide clues for organizing the research on the object. Questions in one domain may lead to information or other questions in another domain.

\section{Diagram}

As illustrated in Figure 1 , the contextual arena surrounds the object. The outer edge of the diagram is an oval, signifying the global and endless circuit that connects each of the domains. Though the domains are connected around the oval, the contextual analysis of the object will not necessarily unfold in a circular fashion. Information and questions will flow back and forth across the diagram. This construct demonstrates the interconnectedness and multi-dimensionality of the world of ceramics. The straight lines emanating from the central object fan out and connect with each domain. How ever, the lines also pass through the object and connect with each other. Each domain must be linked separately to each of

\footnotetext{
${ }^{3}$ Extensive definitions of the domains and their subtopıcs are included in the thesis research.
}

Marilyn Zurmuehlen's Working Papers In Art Education 1996-1997 
the others, as information from one domain often determines information and questions in another domain.

The framework has been designed so that any ceramics object can be placed in the center and analyzed. For example, any of the following objects could be placed in the center of the structure, a Japanese piece trom Bizen. Italian tin-glazed apothecary jar, Delft tile, Greek Krater, Limoges tureen, Peruvian stirrup pot, Adelaide Alsop Robineau's Scarab Vase, Patty Warashina's Kinn Car. Adrian Saxe's antelope jar, Richard Notkin's eco-political vessel, Jim Melchert "clayworks" performance, or Clary llian's functional work.

\section{The Subtopics}

Ceramic objects are made in a particular way, in a particular place, for a particular reason. The subtopics are included in Figure 1 to assist the researcher (teacher or student) in understanding what "type" of information might fall within each topic. The subtopics direct the researcher to specific circumstances of the object within the domains.

The subtopics expose various questions that might be asked within each domain. For instance, typical questions under the (4.0) Visual Qualities domain would be: What is the basic shape (4.1)? ${ }^{4}$ Is the object glazed (4.4)? If the object is not glazed, what method was used to decorate or finish the surface ( 4.5 and 4.7)? Questions within the (2.0) Function domain could be: Was the object used to prepare family meals (2.1)? Did it have ceremonial or ritual uses (2.8) ? Was it made to brighten a dull corner (2.5)?

Some ceramic works connect or contextually read more frequently and more in-depth in a particular domain and might scarcely make contact in others. Some domains will have more sub-topic contact points and therefore more domain interaction. For example, a simple milk pitcher might have many connections to (7.0) Technical Components. It is a stoneware clay body (7.3), composed of wheel thrown and mold construction (7.5), a handle was pulled (7.5 and 7.9), it has cobalt stains (7.7 and 7.8) under a salt glaze (7.8), and it was wood fired (7.11 and 7.12). However, as a simple pitcher, it may have only one contact point in the (2.0) Function domain -it is a utilitarian object and is useful in daily life. It may have several (4.0) Art World Connections. It could have echoes of a (cross-craft) metal pitcher (5.7), it was also influenced by the art deco movement (5.3), and ceramic objects made by well-known ceramists modified the maker's perspective (5.5). Moreover, this pitcher may only reflect in one (8.0) Sociological/ldeological Issue - as a wood fired salt glazed object, trees were destroyed and the air was polluted to create the finish (8.2).

\section{Multi-dimensional Circumstances}

Cultures, artists, traditions, raw materials, and functions alter the set of circumstances of the object, therefore the domains must accommodate variable

\footnotetext{
${ }^{4}$ Numbers in parentheses refer to and correspond with the subtopic numbering system in Figure 1 .
}

Marilyn Zurmuehlen's Working Papers In Art Education 1996-1997 
circumstances. "Multi-dimensional" is used within this research in two contexts: the relationship of the eight domains (or sets of circumstances), and the countless variables (or sub-topics) within each domain. Therefore, the object can be viewed a number of ways using the inventory of references within each domain. A multi-dimensional view is critical to understanding the depth and breadth of the construct. The breadth of the construct is formed by the domain topics; the depth of the construct is built on the variables or subtopics within the domains.

The domains are contextually linked-the circumstances in one domain influence the circumstances in another. For instance, (1.4) Geography, a subtopic in (1.0) Cultural Foundations imposes the type of soils available for the (7.3) Clay Body, a subtopic in (7.0) Technical Components. The type of clays available will modify some aspects of "how" the object was made. How the object was made, influences the variables within (4.0) Visual Qualities. The visual qualities of an object often guide the researcher to the artist's craftsmanship philosophy, a subtopic of (6.0) Production Conditions.

\section{What Could Be the Case for Clay?}

I believe students can be taught all the skills necessary to manipulate materials. If that is all that is taught, then what you have is a very industrialized and machine made result. . . The mind needs to be stretched and fed with much more in a clay program. More emphasis needs to be placed on developing skills through criticism, history and philosophy.

$$
\text { Paragon, 1988, p. } 28
$$

This study is based on my concern for, "What has been the case for clay" (Ecker, 1988, p. 29) in public high school ceramics classes. A new case for clay is pledged to respond to Ecker's question, "What could be the case for clay" (1988, p. 29)? Yet, how does knowing the structure of the world of ceramics - and knowing how to explore the content, help in designing a new case for clay? If teachers used this instrument/structure to unravel the content in the world of ceramics, what is its usefulness toward a new case for clay? What aspects of ceramics education can be analyzed through the structure?

Clearly, ceramic objects and instruction are at the heart of ceramics education. Therefore the structure developed in this study was employed to "read" the context of ceramic objects and to analyze and/or map instruction. The structure of the world of ceramics, as developed in this research, will help us to understand ceramic objects in the most complete way, providing substantive information for ceramics instruction.

\section{Employing the Structure}

\section{Ceramic Objects.}

Ceramics education can be advanced beyond technique and process by analyzing the content of objects. To illustrate the potent contextual space 
available within the construct, contemporary objects were selected as examples for in-depth discussions in the thesis research. Each object discussion was followed by a contextual diagram. The five objects were all made within the last twenty years. Contemporary objects were selected for the contextual discussions. Clark (1983), Rawson (1983), and Shaner (1996) have pointed out that contemporary objects are based on past tradition and technology. This perspective highlights the diversity of contemporary objects, prompts an investigation of broader aesthetic options, and while provides an active dialogue of ceramic object making today.

The discussions were included in the research to illustrate how the "text" of an object can be "read" utilizing the eight domains and their subtopics as depicted in Figure 1. Obviously, the world of ceramics is so extensive that five objects cannot begin to explore global production and social circumstances in the field. However, the objects that were discussed were thoughtfully selected using Clark's (1983) four curatorial classifications (Primal, Decorative, Figural, Architectural) developed for The Contemporary Art Society's Ceramic Echoes Historical References in Contemporary Ceramics exhibit at the Neison-Atkins Museum of Art in Kansas City, Missouri.

The five artists and objects included in the research were: Warren MacKenzie: Bowl (Primal), Andrea Gill: Marie's Madonna (Decorative), Patti Warashina: Coupling (Figural), and Joyce Kozloff: Harvard Square Subway Station - Section III - Folk Art (Architectural). ${ }^{5}$ Because the work of Peter Voulkos created such a shift in philosophical and technical production, a fifth object (a Voulkos Plate/Drawing) was included as the fifth object. One contextual diagram (for Andrea Gill's Marie's Madonna) is included in this paper as an example of how an object can be contextually read (see Figure 2 ). ${ }^{6}$ The contextual discussions in the original study provided a solid and practical foundation for this research, illustrating the utility and application of the structure and diagrams.

\section{Ceramics Instruction}

To determine the workability of the structure and to analyze the breadth and depth of instruction as it applies to the world of ceramics, the structure was used as a template to examine content-based ceramics instruction. A participant observation case study was chosen as the research tool. There were two objectives: (a) to view contemporary ceramics instruction, striving to move beyond the traditional ceramics approach and, (b) to assess the comprehensiveness of the content and instructional activities to substantive

\footnotetext{
${ }^{5}$ Three of the five objects selected for this study were "researched" from reproductions - the research technique usually available to practitioners However, two objects are included in this study as examples of the enhanced layer of information that is only possible from handling the work or seeing it up close. The bowi by Warren Mackenzie was accessible to me and therefore the discussions retlected a hands-on component. It serves as an example of the extension of details available from using an actual object; the discussion on Marie's Madonna reflects personal contact with Andrea Gill and Marie's Madonna

${ }^{5}$ The numbers in parentheses correspond to the subtopic numbers in Figure 1
} 


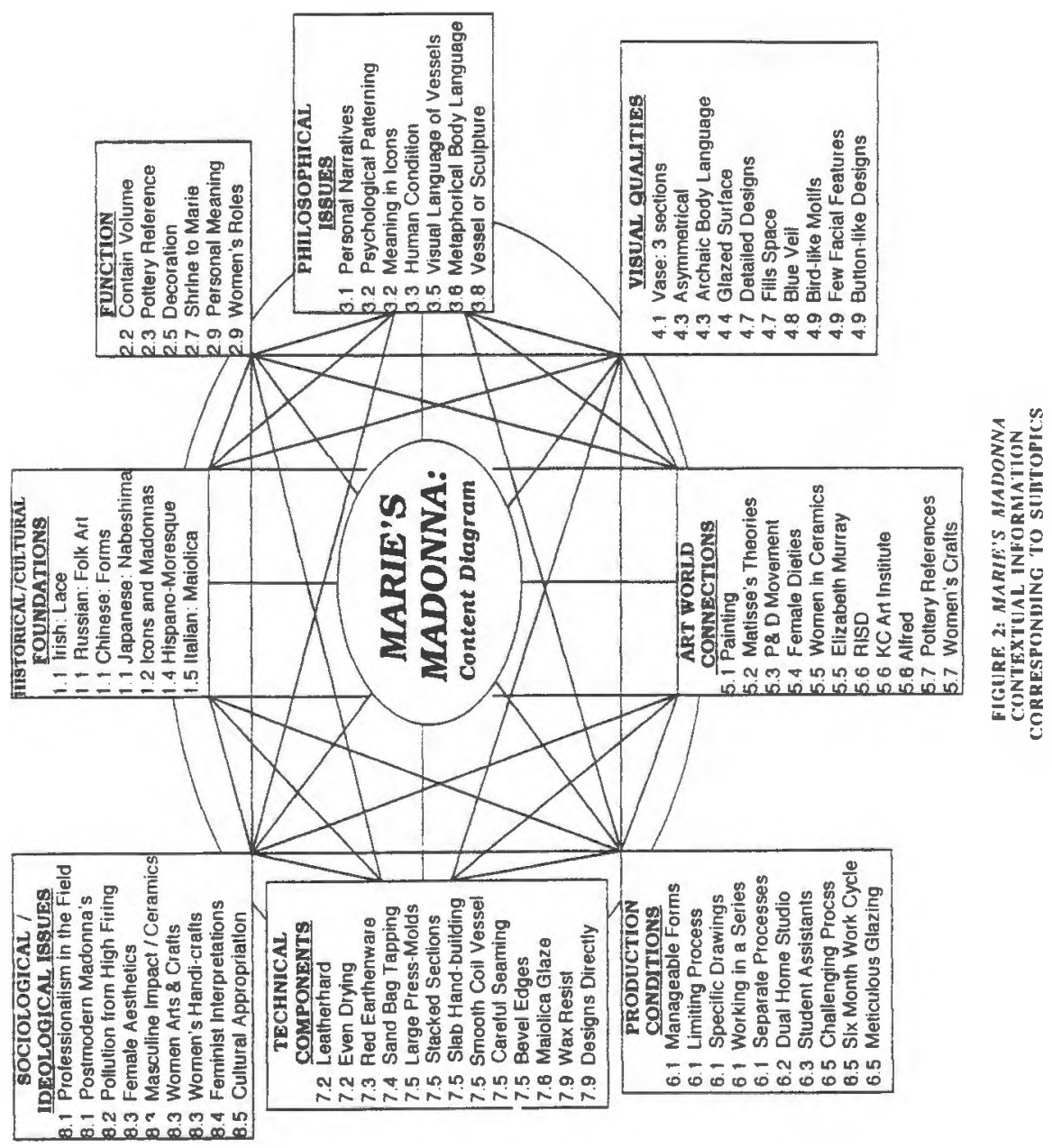

101

Marilyn Zurmuehlen's Working Papers In Art Education 1996-1997 
information determined by the world of ceramics and illustrated in the construct developed in this research.

The criteria for selecting the field site centered on the goal of ceramics instruction in the school, the curricular strategies implemented, and the dedication of the instructor to provide content-based instruction. A classroom was located where the teacher was sincerely devoted to undertaking the difficult transition from traditional studio-based ceramics to a contemporary art education methodology. ${ }^{7}$ Observing the instruction in this kind of classroom conceivably provides an effective site for examining the relationship between the information presented by the teacher and the content available in the world of ceramics.

Two units were presented during the semester case study (i.e., figural sculpture and vessels). The content of all activities, assignments, demonstrations, written assignments and handouts were analyzed according to the structure. The construct provided an effective template for assessing the content and activities of instruction. The structure proved very useful for analyzing the instruction and how domains were activated within the classroom, as well as which topics were latent. Figure 3 is included as an example of how the structure was used to analyze instruction. The diagram illustrates the activated domains and subtopics of the case study. ${ }^{8}$

My research indicated that units of instruction based on content (as illustrated in Figure 1) from the world of ceramics are sparse. When contentbased lessons have been developed, the information and activities generally only touch on information outside of process and technique. Therefore, within the original research, a unit of instruction was developed as an example of how the contextual discussions and the construct could be used to guide instruction/curricular practices. This unit was posited to illustrate the potential for a structure of the world of ceramics to provide a template for planning/organizing instruction or curriculum. The contextual discussion research on Andrea Gill's Marie's Madonna was developed into a unit of instruction as an example for employing the domains/subtopics in the construct.

Marie's Madonna proved to be an excellent ceramics object on which to base a unit of instruction. The vase not only illuminated the structure, but it unearthed pertinent and substantive content for ceramics instruction. It provided a comprehensive and substantive learning experience including European and Asian design influences, sculpture-vessel dialogue, cross-craft contacts, modern-postmodern issues and media, traditional and contemporary ceramic concerns, painter-potter skills, contemporary interpretations and strong art world connections. Components from the unit were designed to activate domains that were latent in the case study (see Figure 3), as well possible ways to include newer classroom technologies (i.e., computer designing, digital appropriation, and a student cyberspace exhib:t).

\footnotetext{
The teacher was striving implement discipline-based ceramics education

'The figures in parentheses following the topics indicate how many times the topic was mentioned or activated during the case study data collecting sessions.
} 


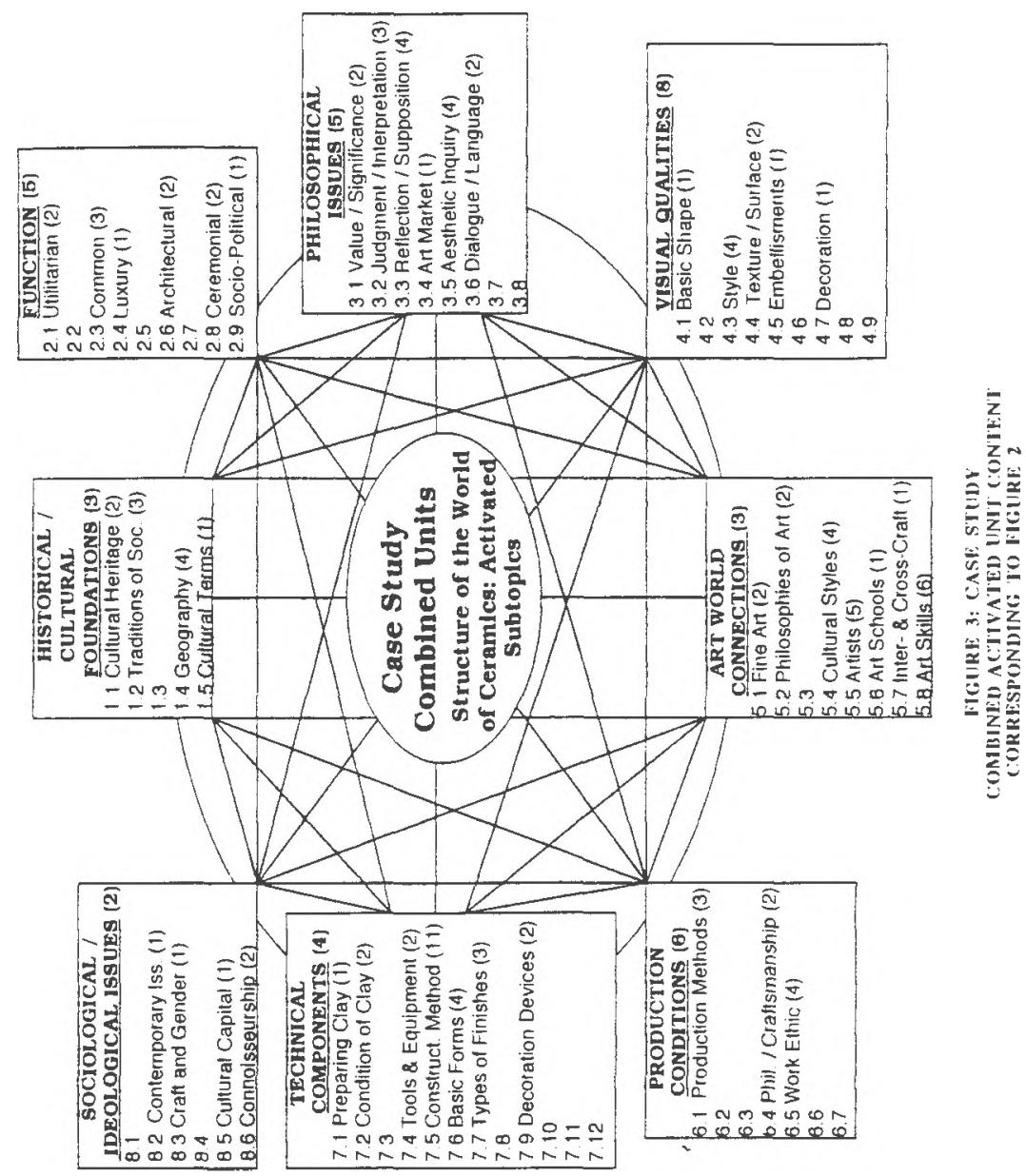

103

Marilyn Zurmuehlen's Working Papers In Art Education 1996-1997 


\section{Summary}

Ceramics is ideally suited to what Silverman recommends for art education, in that "Concepts and media need to be investigated as one seeks to represent and interpret personal experiences, the visual environment, and prevailing attitudes and values" (1988, p. 14). This research explores the multidimensional content and potential of the world of ceramics in a new case for clay or, "what should be the case for ceramics in high schools." Ceramics production can become a conduit to strengthen student learning in a multi-dimensional manner by employing information from the world of ceramics. A new perspective in ceramic education can keep the craftsmanship, creativity and skill level in tact, while concurrently addressing the treasury of educational opportunities. Ceramics can be an active site for investigation, reenactments, dialogue, inquiry and writing activities.

The central elements of this research provide reasonable possibilities for altering the focus and approach of conventional ceramics classrooms. The construct developed in this research maps substantive content in the world of ceramics. The object discussions (in the thesis research) pointed out the strength of the construct for unearthing and organizing contextual information. The case study examined current practice as it relates to analyzing and employing content from the world of ceramics. The unit of instruction illustrated the potential for the construct to prompt and employ instructional practices based on the information available from the world of ceramics.

This study developed a new dimension for ceramics education, positing a construct to ground ceramics education in the history and dialogue of ceramics. Students would explore past, present and future worlds, as well as acquiring global knowledge. Ceramic works of art and their content would be the focus of ceramics education and students would be encouraged to work, think and act like artists. Application of the structure promises substantive content, meaningful experiences and improved education opportunities for ceramics students. Exploration of the structure invites further research for myself and others.

\section{References}

Alexander, K., \& Day, M., (Eds.). (1991). Discipline-based art education: A curriculum sampler. Santa Monica, CA: The Getty Center for Education in the Arts.

Carpenter, S. (1995). Toward a theory of interpretation for contemporary ceramics. The NCECA Journal, 1995.

Clark, G. (1979). Century of ceramics in the United States. New York: E.P. Dutton.

Clark, G. (1983). (Forward)Ceramic echoes.: Historical references in contemporary ceramics. Kansas City, Missouri: The Contemporary Art Society. 
Cooper, E. (1978). History of pottery. New York: St. Martin's.

De Muro, T. (1992). Making a case for clay in art education.

Dissertations Abstracts International, 53(11), 3119.

Ecker, D. (1988). The case for clay in art education [Monograph].

Studio Potter, 16(2), 28-30.

Feldman, E. (1988). The case for clay in art education [Monograph].

Studio Potter, 16(2), 18-23.

Hill, J. (1988). An historical analysis of and speculation about the value of clay working in American education. Dissertation Abstracts International, 4 9(09), 2507.

Hopper, R. (1986). Functional pottery. Radnor, PA: Chilton.

Leach, B. (1948). A potter's book. London: Faber and Faber.

Nelson, G. (1971). Ceramics: A potter's handbook. New York: Holt, Rinehart and Winston.

Paragon, M. (1989). Nurturing a tremendous potential: Response to the nomination for models of excellence. The Case for clay II. Abstract for symposium presentation, San Francisco, CA, November 29, 1989 (symposium cancelled), p. 1-4.

Powell, E. (1973). What can a student get from pottery besides a pot? The Independent School Bulletin, 33(2). 23-25.

Rawson, P. (1983). Echoes: An introduction. In G. Clark (Ed.), Ceramic echoes. (pp. 13-19). Kansas City, Missouri: The Contemporary Art Society.

Rawson, P. (1984). Ceramics. London \& New York: Oxford.

Rice, P. (1990). Functions and uses of archaeological ceramics. In W. Kingery (Ed.), The changing roles of ceramics in stociety: 26,000 B.P. to the present (pp. 1-12). Westerville, $\mathrm{OH}$ : The American Ceramic Society.

Ropko, A. (1977). An introductory secondary school ceramics curriculum model derived from four contemporary value education sources.

Dissertation Abstracts International, 38(11), 7805020-A.

Shaner, D., (1996). Dialogue with the history of clay. Studio Potter, $24(2)$, p. $19-20$

Silverman, R. (1988). The egalitarianism of discipline-based art education, Art Education, 41(2), 13-18. 
Slivka, R. (1978). Peter Voulkos: Diaiogue with clay. New York: Little, Brown and Company.

Stone, P., Dunphy, D., Smith, M., \& Oglivie, D. (1966). The general inquirer: A Computer Approach to Content Analysis. Cambridge, MA: M.I.T.

Walter, H. (1905). History of Ancient Pottery. London: J. Murray. 